\title{
Melanism in Adalia ladybirds and declining air pollution in Birmingham
}

\author{
Paul M. Brakefield* and \\ David R. Lees
}

\author{
Department of Zoology, University College, P.O. Box \\ 78, Cardiff CF1 1XL, U.K.
}

\begin{abstract}
The frequency of the melanic forms of Adalia bipunctata continued to fall at five sites in the Birmingham conurbation after the earlier decline in the 1960 s monitored by $E$. R. Creed. The decline had levelled off by about 1978 . The rate of change in melanic frequency was similar at each site with a more or less constant disadvantage to melanics of about ten percent from 1960 to 1978 . The pattern of change shows a close correspondence to the levels of smoke pollution in Birmingham $(r=+0.91)$ but a weaker association with sulphur dioxide $(r=+0.72)$. It is argued that this follows from an influence on thermal melanism via the effect of smoke in reducing sunshine. The related $A$. decempunctata shows no changes in melanic frequencies at the same sites. This is consistent with previously inferred evidence for a lack of any influence of thermal melanism in this species. The responses of these ladybird beetles to changing air pollution are compared with that in the moth Biston betularia.
\end{abstract}

\section{INTRODUCTION}

Creed $(1966,1971 a)$ showed that the warninglycoloured two-spot ladybird beetle Adalia bipunctata (L.) exhibits industrial melanism in Britain, there being a positive correlation between the frequency of melanic forms and the level of smoke pollution but a weaker association with sulphur dioxide. He also (Creed, 1971b) detected a decline of about 15 per cent in the frequency of the melanic forms at six sites in or near Birmingham in the 1960s shortly after the passing of clean air legislation in 1956 and the consequent introduction of smokeless zones. Bishop, Cook and Muggleton (1978) provide support for a similar decline at eight sites in northwest England from a comparison of Creed's (1971a) survey with their own samples, mostly collected in 1976. Creed suggested that smoke has some direct selective influence on melanics. In contrast, Muggleton, Lonsdale and Benham (1975) present an alternative explanation that the correlations arise from the effect of smoke reducing solar radiation reaching the ground. The associated theory of thermal melanism predicts that melanic beetles gain an advantage under conditions of low sunshine because of their more efficient heat absorption than non-melanics

\footnotetext{
* Present address: Zoology Laboratory, University of Leiden, Kaiserstraat 63, 2300 RA Leiden, The Netherlands.
}

(Muggleton et al., 1975; Brakefield and Willmer, 1985). Evidence for influences of thermal melanism on the reproduction of $\boldsymbol{A}$. bipunctata has been obtained by Brakefield (1984a, b).

The decline in melanic frequencies in A. bipunctata in Birmingham was substantial some ten years or so before those documented in the peppered moth Biston betularia in England and Wales (Lees, 1981; Clarke, Mani and Wynne, 1985; Cook, Mani and Varley, 1986). An understanding of such differences between species in the dynamics of responses to changes in air pollution is likely to provide insights into the underlying causal mechanisms. In this paper we give a more complete analysis of data covering 26 years for A. bipunctata from five of Creed's (1971b) Birmingham sites based on samples collected by E. R. Creed (unpublished data) and by ourselves. We also examine corresponding, but more limited data for the 10 spot ladybird $A$. decempunctata (L.). Differences in the responses shown by these beetles and $B$. betularia are discussed in the light of proposed selective processes.

\section{MATERIALS AND METHODS}

The data for each of five sites in the Birmingham conurbation (fig. 1) for 1960 to 1978 were 


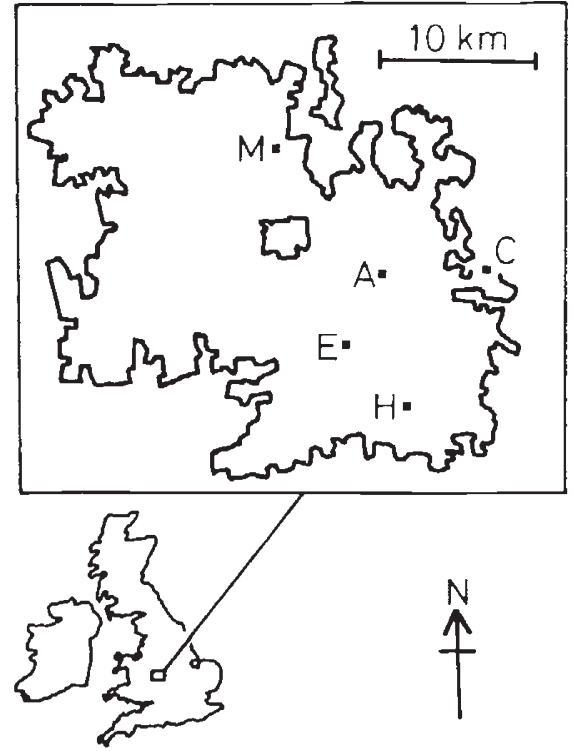

Figure 1 Outline map of the Birmingham conurbation in Great Britain showing the positions of the five sampling sites in this and Creed's (1971b) study. A=Aston Church; $\mathrm{C}=$ Castle Bromwich; $\mathrm{E}=$ Edgbaston; $\mathrm{H}=$ Hall Green; $\mathrm{M}=$ Maw Green.

abstracted from the late E. R. Creed's records (Creed, 1971b gives details of four small samples from a sixth site). We obtained further samples from the exact localities of the five sites in 1986. Many samples consisted of adults emerging in the laboratory from pupae collected on lime trees, Tilia spp., or nettle, Urtica dioica. The majority of non- melanics were of the typica form. The distinction between the two melanics, quadrimaculata and sexpustulata, is not always clear, especially in beetles raised from pupae, and in this paper they are grouped together. Data from the same sources for the frequency of the non-melanic (typica), intermediate (decempustulata) and melanic (bimaculata) forms of $A$. decempunctata are also analysed (for illustrations see Brakefield, 1985).

\section{RESULTS}

Table 1 presents the data for $A$. bipunctata. Fig. 2 shows that the declines in the frequency of melanics in the 1960 s described by Creed (1971b) continued in the 1970 s but chi-square comparisons of the combined data for the 3 years 1976 to 1978 against 1986 show that there were no further changes in melanic frequency over this later period $(P>0 \cdot 1$ for each site). The three geographically well separated sites (fig. 1) with initial frequencies of about forty per cent melanics show a closely similar pattern of changing frequency. Edgbaston and Castle Bromwich with higher and lower melanic frequencies respectively, show a similar rate of decline. Fig. 2 shows that the decline at the five sites is approximately linear over the period 1960 to 1978 . An analysis of the data presented in fig. 2 over this period shows no significant differences between the five linear regressions $(F=1 \cdot 25$, $\mathrm{df}=4$ and $33, P$ is NS; range in values of $b:-1 \cdot 38$ to -2.32 per cent per year with $P<0.05$ for each).

Table 1 Numbers of non-melanic ( $\mathrm{n}-\mathrm{m}$ ) and melanic (mel) Adalia bipunctata in annual samples from sites in the Birmingham conurbation from 1960 to 1986

\begin{tabular}{|c|c|c|c|c|c|c|c|c|c|c|}
\hline Year & $\begin{array}{l}\text { Aston } \\
n-m\end{array}$ & $\begin{array}{l}\mathrm{rch} \\
\mathrm{mel}\end{array}$ & $\begin{array}{l}\text { Castle } \\
n-m\end{array}$ & $\begin{array}{c}\text { Bromwich } \\
\text { mel }\end{array}$ & $\begin{array}{l}\text { Egbaston } \\
n-m\end{array}$ & mel & $\begin{array}{l}\text { Hall Green } \\
n-m\end{array}$ & mel & $\begin{array}{l}\text { Maw Green } \\
n-m\end{array}$ & niel \\
\hline 1960 & - & - & 47 & 21 & 55 & 64 & - & - & - & - \\
\hline 1961 & - & - & - & - & 15 & 39 & 5 & 6 & 27 & 18 \\
\hline 1962 & - & - & - & - & 51 & 65 & 44 & 42 & 51 & 28 \\
\hline 1963 & - & - & - & - & 2 & 5 & - & - & - & - \\
\hline 1964 & 36 & 26 & 51 & 17 & - & - & 30 & 17 & 109 & 71 \\
\hline 1965 & 15 & 12 & - & - & - & - & 33 & 18 & 41 & 23 \\
\hline 1967 & 244 & 77 & 108 & 23 & - & - & 132 & 58 & 119 & 54 \\
\hline 1968 & 4 & 3 & 48 & 5 & - & - & 54 & 21 & 106 & 38 \\
\hline 1969 & 106 & 41 & 40 & 12 & 87 & 91 & 61 & 29 & 97 & 32 \\
\hline 1970 & 128 & 33 & 31 & 5 & - & - & 70 & 25 & - & $\cdots$ \\
\hline 1971 & 29 & 8 & $\ldots$ & - - & - & - & 51 & 13 & - & - \\
\hline 1972 & 70 & 22 & 186 & 35 & - & - & 64 & 13 & - & - \\
\hline 1974 & 131 & 19 & - & - & - & - & 150 & 36 & - & - \\
\hline 1975 & - & - & - & - & 4 & 6 & - & - & - & - \\
\hline 1976 & 207 & 25 & - & - & 19 & 6 & 131 & 15 & 71 & 14 \\
\hline 1977 & 154 & 24 & 19 & 0 & 114 & 48 & 271 & 33 & - & - \\
\hline 1978 & 31 & 1 & - & - & 27 & 13 & - & - & - & -- \\
\hline 1986 & 46 & 5 & 2 & 0 & 251 & 84 & 167 & 12 & 85 & 9 \\
\hline
\end{tabular}




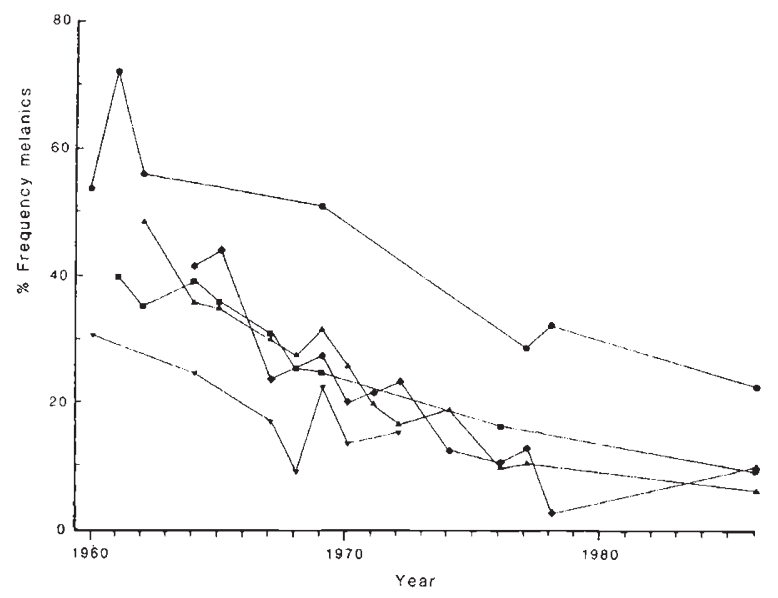

Figure 2 Change in frequency of the melanic forms of Adalia bipunctata in the Birmingham conurbation from 1960 to 1986. Sites: - Aston Church; V, Castle Bromwich; $\mathbf{O}$, Edgbaston; $\boldsymbol{\Lambda}$, Hall Green; $\boldsymbol{\square}$, Maw Green. Minimum sample size $=30$.

The "common" regression coefficient indicates a decline in melanic frequency of 1.93 per cent per year from an average $y$-intercept of 45.8 per cent. Application of the method used by Cook et al. (1986) shows that this relationship corresponds to a constant selective disadvantage to melanics of about 10 per cent since 1960 .

Fig. 3 compares the overall regression of melanic frequency on time with the average levels of smoke and sulphur dioxide at all monitoring sites for Birmingham (Warren Spring Laboratory, 1963-84). Pollution data were abstracted for the months of May, June and July which covers the main perid of adult reproduction (Brakefield, 1984c). Caution must be applied in interpreting these data for two main reasons: (a) lack of continuity of pollution monitoring at particular sites; (b) some heterogeneity in pollution levels between sites. Fig. 3 shows that the fall in the level of smoke is similar to that in melanic frequency in A. bipunctata (correlation between frequencies predicted from the common regression line and levels of smoke $=+0 \cdot 91)$. The amount of smoke also levels off at about the same time as melanic frequency. There is somewhat less parallel with the sulphur dioxide data although the corresponding correlation remains high $(r=+0.72)$. The pollution data for Birmingham since the implementation of clean air legislation tend to parallel national trends, with more rapid declines in annual emissions of smoke than of sulphur dioxide (see Lees, 1981), although apparently there was also some initial decline of sulphur dioxide in the early 1960s in Birmingham (fig. 3). In general there is some time lag between change in amount of sulphur dioxide and that in melanic frequency with the former continuing to decline to the present day.

The combined samples of $A$. decempunctata show that there is no heterogeneity between sites in morph frequencies $\left(\chi^{2}=8 \cdot 27, \mathrm{df}=8, P\right.$ is NS). Table 2 gives the data for each site combined by decade. There is no evidence for any comparable changes in melanic frequencies in $A$. decempuctata to those in $A$. bipunctata (chi-square comparisons of $1960 \mathrm{~s} \times 1970 \mathrm{~s}: P$ is NS for each site). Edgbaston is the only site at which more than 30 beetles were obtained in 1986. This site shows no heterogeneity over the three decades $\left(\chi^{2}=1.81, \mathrm{df}=4, P\right.$ is NS $)$.

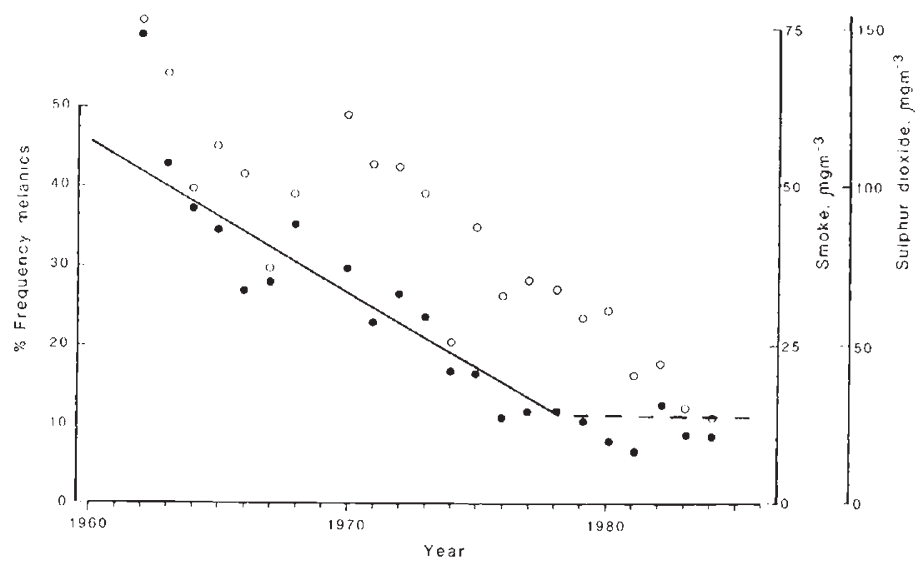

Figure 3 The relationships between the "common" regression slope (solid line) of melanic frequency against time and annual amounts of smoke $(0)$ and sulphur dioxide $(\bigcirc)$ in May to July in Birmingham. The dashed line indicates the period of more or less stable melanic frequencies. 
Table 2 Numbers and percentage frequencies of the non-melanic (typ.), intermediate (dec.) and melanic (bim.) forms of Adalia decempunctata in combined samples for each of three decades from sites in the Birmingham conurbation

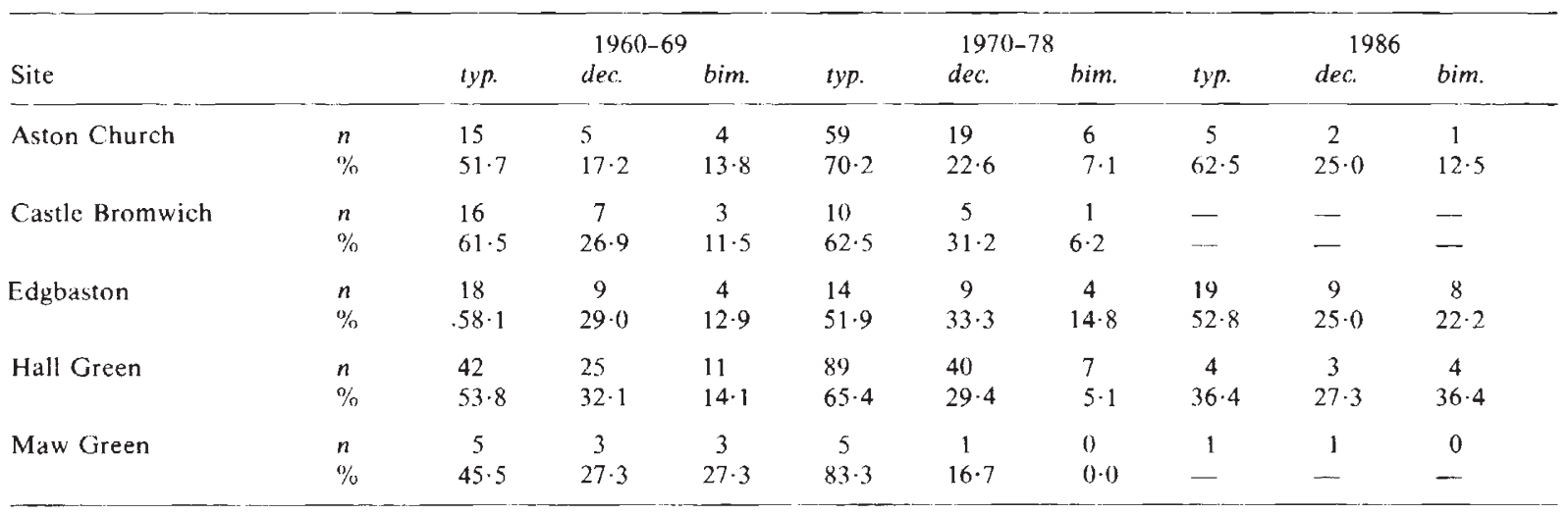

\section{DISCUSSION}

Our analysis shows that the decline of melanic frequency in A. bipunctata monitored in Birmingham by Creed (1971 b) in the 1960 s continued until towards the end of the 1970 s. Creed points out that data of Hawkes (1927) collected in the 1920s suggest that there was also some reduction in melanics prior to the 1960 s. The decrease from 1960 to 1978 was associated with a more or less constant disadvantage to melanics of about 10 per cent compared to the selection regime prior to the decline. It is of a similar timing and pattern to the fall in smoke pollution in Birmingham over the same period (fig. 3). This fall in smoke began in the mid-1950s. The decline in melanic frequency is less similar to the change in levels of sulphur dioxide and supports Creed's (1971a) finding of a substantially weaker association between geographical variation in melanic frequency in $A$. bipunctata and sulphur dioxide than smoke.

At first sight the relationship between falling levels of smoke and melanic frequency is straightforward, but if the strength of selection on melanism tracks the environmental change one might expect that melanic frequency would decrease more rapidly than the amount of smoke. The apparent coincidence in the cessation of changes in melanic frequency and in smoke pollution argues for some selective influence related to continuing environmental change rather than for the initial decrease in pollution triggering a switch from one equilibrium to another, lower one. The decline in melanic frequency appears to be independent of the initial frequency of melanics which varies among the populations. This variability is additional evidence against the existence of two alternative equilibria in Birmingham. The differences in frequency between sites could be associated with local variation in smoke pollution but the pollution data are not good enough to test this.

The data describing the declines in the frequency of melanic $A$. bipunctata in Birmingham cannot in themselves indicate the nature of the selective influence of smoke. However, although we cannot refute the possibility that smoke has some direct selective effect favouring melanics (after Creed, 1966, 1971a, b), there are some other data supporting the hypothesis of a causal association between the effect of smoke in reducing solar radiation and thermal melanism (Muggleton et al., 1975; Brakefield, 1984a, b). This hypothesis predicts that as smoke emissions decline, solar radiation increases at ground level and the thermal advantage of melanics is reduced, via effects on adult fitness, especially reproduction (Brakefield, $1984 \mathrm{a}, \mathrm{b})$. Such an effect of lowered smoke pollution on adult reproduction should be detectable in the next generation. No corresponding mechanism has been indicated with regard to direct influences of smoke although a number could be postulated, for example one based on the effect of small particles on the permeability of the cuticle (see Ebeling, 1971).

The lack of any temporal change in morph frequency in $A$. decempunctata paralleling that in $A$. bipunctata is consistent with the operation of thermal melanism rather than a direct influence of smoke. Thus, Brakefield (1985) shows that this species exhibits no geographical variation in The Netherlands, whereas $A$. bipunctata shows steep clines over the same region. He also found that the strictly arboreal habit of this species, in contrast to $A$. bipunctata, predicts that thermal melanism is unlikely to have any significant influence on 
adult reproduction. Any direct effect of smoke on the polymorphism in $A$. bipunctata might be predicted to operate also on the phenotypically similar polymorphism in the closely related species, $A$. decempunctata.

The substantial decline in melanic frequency in $A$. bipunctata began about 10 years earlier than that in a population of $B$. betularia at West Kirby near Liverpool (Clarke et al., 1985) and more generally in this species in England and Wales (Lees, 1981; Cook et al., 1986). The decline in melanic $A$. bipunctata is associated with a similar selective disadvantage to that estimated at 12 per cent in $B$. betularia (Cook et al., 1986), but the decrease in the carbonaria form of $B$. betularia is more closely correlated with sulphur dioxide pollution than smoke. Gaseous pollutants act, at least in part through effects on the recovery of epiphytic growth on the resting backgrounds of this cryptic moth (see e.g. Liebert and Brakefield, 1987). This indirect effect and the later fall in emissions of sulphur dioxide than of smoke could account for the later decline in melanic frequencies in $B$. betularia than in A. bipunctata.

Acknowledgements This paper is dedicated to the late Robert Creed. He initiated this work and provided the bulk of the data. Our great debt to him will be obvious to all readers. We thank John Endler and an anonymous referee for valuable comments on the manuscript.

\section{REFERENCES}

BISHOP, J. A., COOK, L. M. AND MUGGLETON, J. 1978. The response of two species of moths to industrialisation in North West England. I. Polymorphism for melanism. Phil. Trans. Roy. Soc. (London), 218B, 489-515.

BRAKEFIELD, P.M. 1984a. Ecological studies on the polymorphic ladybird Adalia bipunctata in The Netherlands. II Population dynamics, differential timing of reproduction and thermal melanism. J. Anim. Ecol., 53, 775-790.
BRAKEFILD, P. M. 1984b. Selection along clines in the ladybird Adalia bipunctata in The Netherlands: A general mating advantage to melanics and its consequences. Heredity, 53, 37-49.

BRAKEFILD, P.M. $1984 c$. Ecological studies on the polymorphic ladybird Adalia bipunctata in The Netherlands. I. Population biology and geographical variation in melanism. $J$ Anim. Ecol., 53, 761-774.

BRAKEFIELD, P. M. 1985. Polymorphic Müllerian mimicry and interactions with thermal melanism in ladybirds and a soldier beetle, a hypothesis. Biol. J. Linn. Soc, 26, 243-267.

BRAKEFIELD, P. M., AND WILLMER, P. G. 1985. The basis of thermal melanism in the ladybird Adalia bipunctata: Differences in reflectance and thermal properties between the morphs. Heredity, 54, 9-14.

CLARKE, C. A., MANI, G. S., AND WYNNE, G. 1985. Evolution in reverse, clean air and the peppered moth. Biol. J. Linn. Soc., 26, 189-199.

COOK, L. M., MANI, G.S. AND VARLEY M. E. 1986. Postindustrial melanism in the peppered moth. Science, 231, 611-613.

C.REED, E. R. 1966. Geographic variation in the two-spot ladybird in England and Wales. Heredity, 21, 57-72.

CREED, E. R. 1971 a. Melanism in the two-spot ladybird, Adalia bipunctata, in Great Britain. In Creed, E. R. Ecological Genetics and Evolution (ed.) Blackwell Scientific Publications, Oxford, pp. 134-151.

CREED, E. R. 1971 b. Industrial melanism in the two-spot ladybird and smoke abatement. Evolution, 25, 290-293.

ebeling, W. 1971. Sorptive dusts for pest control. Ann. Rev. Ent., 16, 123-158.

HAWKES, O. A. M. 1927. The distribution of the ladybird Adalia bipunctata L. (Coleoptera). Entomol. Mon. Mag., 63, 262266.

LEES, D. R. 1981. Industrial melanism, Genetic adaptation of animals to air pollution. In Bishop, J. A. and Cook, L. M. (eds.) Genetic Consequences of Man Made Change, Academic Press, London, pp. 129-176.

LIEBERT, T. G. AND BRAKEFIELD, P. M. 1987. Behavioural studies on the peppered moth Biston betularia and a discussion of the role of pollution and epiphytes in industrial melanism. Biol. J. Linn. Soc., 30, (in press).

MUGGLETON, M., LONSDALE, D. AND BENHAM, B. R. 1975. Melanism in Adalia bipunctata L. (Col., Coccinellidae) and its relationship to atmospheric pollution. J. Appl. Ecol., $12,451-464$. 